\title{
Bolton's Ratios for Indian Population, Can We Follow The Ideal Standards Blindly?
}

\author{
Vishwajitsinh J Jhala ${ }^{1}$, Hina Desai ${ }^{2}$, Mohammed Shahid Dal ${ }^{3}$, Nikunj Patel ${ }^{4}$, \\ Kalpesh Patel ${ }^{5}$

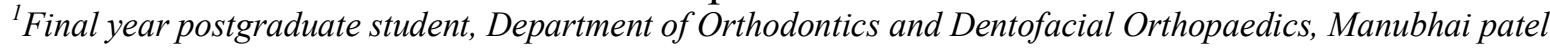 \\ dental college, hospital and oral research institute, Vadodara. \\ ${ }^{2}$ Professor and Head of Department, Department of Orthodontics and Dentofacial Orthopaedics, Manubhai \\ patel dental college, hospital and oral research institute, Vadodara. \\ ${ }^{3}$ Senior lecturer, Department of Orthodontics and Dentofacial Orthopaedics, Manubhai patel dental college, \\ hospital and oral research institute, Vadodara. \\ ${ }^{4}$ Senior lecturer, Department of Orthodontics and Dentofacial Orthopaedics, Manubhai patel dental college, \\ hospital and oral research institute, Vadodara. \\ ${ }^{5}$ Reader, Department of Orthodontics and Dentofacial Orthopaedics, Manubhai patel dental college, hospital \\ and oral research institute, Vadodara.
}

\begin{abstract}
:
Introduction: Various studies have been conducted which show that interarch tooth size relation differ with population. The aim of this study was to find out Bolton ratio in Indian population.

Methods: Measurement were taken from 50 study models of randomly selected males and females with class I molar and canine relationship with ideal overjet and overbite, who had not undergone any orthodontic or cosmetic dental treatment previously. Needle point dividers were used to measure the greatest mesio-distal diameter of all teeth. From the obtained data, the Kolmogrov-Smirnov test, standard error of mean, standard deviation, coefficient of variation, coefficient of correlation were measured and used to assign statistical significance.

Results: Increased anterior ratio (79.2284) \& decreased overall ratio (90.9464) in selected Indian population were found in relation to Bolton's ideal ratio. Conclusions: - Differences between original Bolton ratio and obtained ratio for Indians were significant, specific standards for Indians might be needed.
\end{abstract}

Key Words: Bolton analysis, Indian population, anterior ratio, total ratio, orthodontics

\section{Introduction:}

Orthodontic treatment planning is decided by the amount of space available and amount of space required. To find out proportionate tooth size, different methods are used. The Bolton's analysis ${ }^{1,2}$ is the most widely used method.

There are two indices in Bolton's analysis. Anterior index which is obtained by dividing the mesiodistal size of 6 mandibular anterior teeth (canine to canine) by the mesiodistal size of the 6 maxillary anterior teeth; the overall index is obtained by dividing the mesiodistal size of the 12 mandibular teeth (first molar to first molar) by the mesiodistal size of the 12 maxillary teeth.

The indices from Bolton's study for a correct occlusion were anterior ratio $=77.2 \%$, SD $1.65 \%$, and total ratio $=91.3 \%$, SD $1.91 \%$. Bolton suggested that a ratio greater than $1 \mathrm{SD}$ from his reported mean values indicates a possible treatment need. ${ }^{1,2}$ Other authors have defined a significant discrepancy as a value outside 2 SD from Bolton's means. ${ }^{3,4}$

Different interarch tooth sizes were present in different population. There were no individual values for males and females; a single value was accepted for both males and females. ${ }^{5}$

Therefore, the aim of this study was to use a method to determine anterior and total tooth width ratios in Indian population and compare them with the Bolton standards.

Along with this, the study also includes comparison of Bolton standards with studies conducted by various other authors (as given in Table II).

\section{Material And Methods}

Fifty pairs of dental casts of students all belonging to different parts of India (30 females and 20 males with mean age of 19.2 years \{range: 18.0-21.0 years\}), were selected for this study.

The selection criteria of the sample were (1) permanent dentition from first molar to first molar, (2) good-quality study models, (3) no tooth agenesis or extractions, (4) no large restorations that could change the 
mesiodistal diameter of the tooth, and (5) no teeth with anomalous shapes (6) Class I molar and canine relationship with ideal overjet and overbite.

Three inch needle pointed divider was used to determine the greatest mesiodistal diameter of all the teeth on each cast, except second and third molars. The dimensions to the nearest one quarter millimeter were taken from a finely calibrated millimeter ruler and recorded.

Table I. Anterior and total means, SD, and 95\% CI for maxillary-to-mandibular tooth-width ratios

\begin{tabular}{|c|c|c|c|}
\hline Tooth ratios & Mean (\%) & SD (\%) & 95\% CI (\%) \\
\hline Anterior & 78.96 & 3.6 & $(77.92-80.01)$ \\
\hline Total & 91.45 & 2.7 & $(90.67-92.23)$ \\
\hline
\end{tabular}

Table II. Anterior and total ratios for various populations compared with our study

\begin{tabular}{|c|c|c|}
\hline & Anterior & Total \\
\hline White Americans & & 91.3 \\
\hline Bolton $^{1,2}$ & 77.2 & 91.4 \\
\hline Crosby and Alexander $^{3}$ & 77.5 & 92.3 \\
\hline Smith et al & \\
\hline Spanish (Spain) & 79.6 & 93.39 \\
\hline Fernandez-Riveiro et al $^{10}$ & 80.62 & 91.97 \\
\hline Paredes $^{6}$ & 78.32 & 93.1 \\
\hline Spanish (South America) & & 93.4 \\
\hline Smith et al $^{5}$ & 80.5 & \\
\hline Blacks Smith et al & & \\
\hline Dominican Americans & 79.3 & 91.3 \\
\hline Santoro et al & & \\
\hline Peruvians & 78.1 & $90.79-91.33$ \\
\hline Burkish Bernabé et al $^{8}$ & 78.09 & 89.8 \\
\hline Tancan Uysal et al & & \\
\hline
\end{tabular}

\section{Results}

The results are summarized in Tables I and II. The Kolmogorov-Smirnov test showed a regular frequency distribution for both the anterior and the total tooth widths ratios, so we could use parametric statistical tests.

Mean values and standard deviations for maxillary to mandibular anterior tooth-width ratios were $78.96 \% \pm 3.6 \%$ and total tooth-width ratios were $91.45 \% \pm 2.74 \%$ for females and males, respectively, with a $\mathrm{P}$ value of 0.084 .

No significant differences were found in anterior and total tooth-width ratios according to sex $(\mathrm{P}=.084$ respectively), so the groups were combined, and new anterior and total ratios were calculated: $78.96 \%$ and $91.45 \%$, respectively (Table I).

Table II compares anterior and total ratios for various populations (white and Dominican Americans, blacks, Spanish, Peruvians, Turkish, Indians) as reported by several authors.

The anterior and total tooth-size discrepancies outside the 2-SD range from the Bolton means were also calculated for our sample; the results were $4 \%$ and $4 \%$, respectively.

\section{Discussion}

The Bolton sample was obtained from 55 models with excellent occlusion - 44 orthodontically treated and 11 untreated. In our sample, all 50 pairs of models had optimal occlusions-Class I with no arch discrepancy with a mean age of 19 years (range, 18-22 years); so a direct statistical comparison between groups was possible. We did not consider incisor inclination, just tooth sizes for Bolton ratios.

For the total and anterior ratios, the means and the standard deviations, considering the 95\% CI, were larger in this study than in Bolton's. The values were similar to those reported by Bernabé et $\mathrm{al}^{9}$ and Santoro et $\mathrm{al}^{7}$ for the anterior ratio and by Bernabé et al and Smith et $\mathrm{al}^{5}$ for the total ratio (Table II).

The anterior ratios values were larger than the Bolton standards in all of them, but total ratios were similar to Bolton's standards.

If a standard deviation greater than 2 indicates a significant discrepancy, an anterior ratio below 71.6 or above 86.32 and a total ratio below 96.93 or above 85.97 would be considered clinically significant.

A significant discrepancy in the anterior ratio was found in $4 \%$ of the Indian sample (4\% less than 2 $\mathrm{SD})$ On the other hand, a discrepancy in the total ratio was also found in $4 \%$ of the Indian patients ( $4 \%$ greater than $2 \mathrm{SD}$ ) 


\section{Conclusions}

Thus from the study conducted above, we can say that Bolton's analysis cannot be applied in every ethnicity and hence specific values are needed for different ethnicity.

Mean anterior and total tooth-width ratios between males and females are not statically significantly different; therefore, combined mean anterior and total tooth-width ratios are given: $78.96 \% \pm 3.6 \%$ and $91.4 \% \pm$ $2.74 \%$, respectively.

The relationship between the sizes of the mandibular and maxillary teeth depends on population.

The anterior and total ratios for Indian sample are greater than Bolton's. The differences are statically significant and suggest the need for specific standards for the Indian population.

A statically significant anterior discrepancy was found in $4 \%$ of the patients in the sample, and $4 \%$ had a total discrepancy greater than 2 SD from Bolton's standards.

\section{References}

[1]. Bolton WA. Disharmony in tooth size and its relation to the analyses and treatment of malocclusion. Angle Orthod 1958;28:113-30

[2]. Bolton WA. The clinical application of a tooth-size analysis. Am J Orthod 1962;48:504-29.

[3]. Crosby DR, Alexander CG. The occurrence of tooth size discrepancies among different malocclusion groups. Am J Orthod Dentofacial Orthop 1989;95:457-61

[4]. Freeman JE, Maskeroni AJ, Lorton L. Frequency of Bolton tooth-size discrepancies among orthodontic patients. Am J Orthod Dentofacial Orthop 1996;110:24-7.

[5]. Smith SS, Buschang PH, Watanabe E. Interarch tooth size relationships of 3 populations: “does Bolton's analysis apply?”Am J Orthod Dentofacial Orthop 2000;117:169-74.

[6]. Paredes V. aredes V, Gandia LJ, Cibrian R. New, fast, and accurate procedure to calibrate a 2-dimensional digital measurement method. Am J Orthod Dentofacial Orthop 2005;127:518-9.

[7]. Santoro M, Ayoub ME, Pardi VA, Cangialosi TJ. Mesiodistal crown dimensions and tooth size discrepancy of the permanent dentition of Dominican Americans. Angle Orthod 2000;70:303-7.

[8]. Bernabé E, Major PW, Flores-Mir C. Tooth-width ratio discrepancies in a sample of Peruvian adolescents. Am J Orthod Dentofacial Orthop 2004;125:361-5.

[9]. Tancan Uysal et al; Intermaxillary tooth size discrepancy and mesiodistal crown dimensions for a Turkish populationAm J Orthod Dentofacial Orthop 2005;128:226-30

[10]. Fernández-Riveiro P, Suárez-Quintanilla D, Otero-Cepeda JL. Análisis odontométrico de una población maloclusiva: índice de Bolton. Rev Esp Ortod 1995;25:119-26. 